\title{
Severe odynophagia in a patient developing after azithromycin intake: a case report
}

Umit Akyuz ${ }^{1}$, Yusuf Erzin ${ }^{1 *}$, Fevzi Firat Yalniz², Ibrahim Volkan Senkal ${ }^{2}$, Isin Dogan Ekici ${ }^{3}$, Cengiz Pata ${ }^{1}$

\begin{abstract}
Introduction: Drug-induced esophageal ulcers most commonly cause heartburn, midsternal pain and dysphagia. In our clinic azithromycin is a relative widely used antibiotic for respiratory tract infections and otitis media because of its activity against Haemophilus influenzae and atypical pathogens, and its ease of administration. After a thorough search in Pubmed the present case is the first one to report azithromycin-induced esophageal ulcer and associated symptoms in the literature.

Case presentation: A 61-year-old Caucasian man was admitted to our endoscopy unit for the investigation of odynophagia and retrosternal pain of new onset. His past medical history was unremarkable but had used azithromycin $500 \mathrm{mg} / \mathrm{d}$ for three days in the previous week. An upper endoscopy revealed an extensive serpiginous midesophageal ulcer in the presence of a normal squamocolumnar junction and biopsies from the edges and center of the lesion disclosed no neoplasia or infectious causes but a dense acute inflammatory infiltrate. The patient was put on a liquid diet, sucralfate proton pump inhibitor treatment and was symptom-free within two weeks. After four weeks on therapy a repeated upper endoscopic control examination demonstrated normal findings.

Conclusion: To our knowledge this is the first such a case of azithromycin -induced esophageal ulceration. We think that a little time taken by the physician to warn the patients for taking every oral drug with sufficient amount of water might prevent this kind of complications.
\end{abstract}

\section{Introduction}

It is well established that various drugs can cause esophageal mucosal injury, tetracycline, doxycycline, quinidine, potassium chloride and emepronium bromide accounting for $90 \%$ of reported cases [1]. Severity of injury ranges from mild inflammatory changes to severe ulceration, perforation or stricture formation. Common reason of this complication has been taking medications just before bedtime, and with a small amount of water $[1,2]$. In this report a patient who developed esophageal ulcers after taking azithromycin (AZM) for upper respiratory tract infection is presented.

\section{Case presentation}

A 61-year-old Caucasian man was admitted to our outpatient clinic with complaints of heartburn, midsternal pain, dysphagia and odynophagia for one week. He was

\footnotetext{
* Correspondence: dryusuferzin@yahoo.com

'Department of Gastroenterology, Yeditepe University Medical Faculty,

Devlet Yolu Cad 102-104 34752 Kozyatagi, Istanbul, Turkey
}

a nonsmoker and denied any use of alcohol, aspirin or non-steroidal anti inflammatory drugs. His past medical history was unremarkable but had used AZM $500 \mathrm{mg} / \mathrm{d}$ for three consecutive days after which his complaints began. His physical examination was normal. He had no fever, his cardiac and chest auscultation and throat examinations were normal. An electrocardiography and chest $\mathrm{x}$-ray revealed no pathological findings. An upper endoscopy revealed an extensive serpiginous midesophageal ulcer in the presence of a normal squamocolumnar junction (Figure 1). Biopsies from the edges and center of the lesion disclosed no neoplasia or infectious causes but a dense acute inflammatory infiltrate (Figure 2). The ulceration was thought to be due to AZM intake and the patient immidiately was put on a liquid diet, and sucralfate $1 \mathrm{~g}$. qid, and esomeprazole $40 \mathrm{mg}$. bid treatment and got symptom-free within two weeks. A control endoscopy demonstrated completely normal findings after four weeks of therapy.

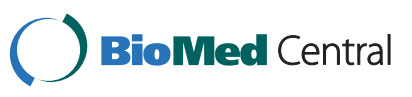

(c) 2010 Akyuz et al; licensee BioMed Central Ltd. This is an Open Access article distributed under the terms of the Creative Commons Attribution License (http://creativecommons.org/licenses/by/2.0), which permits unrestricted use, distribution, and reproduction in any medium, provided the original work is properly cited. 


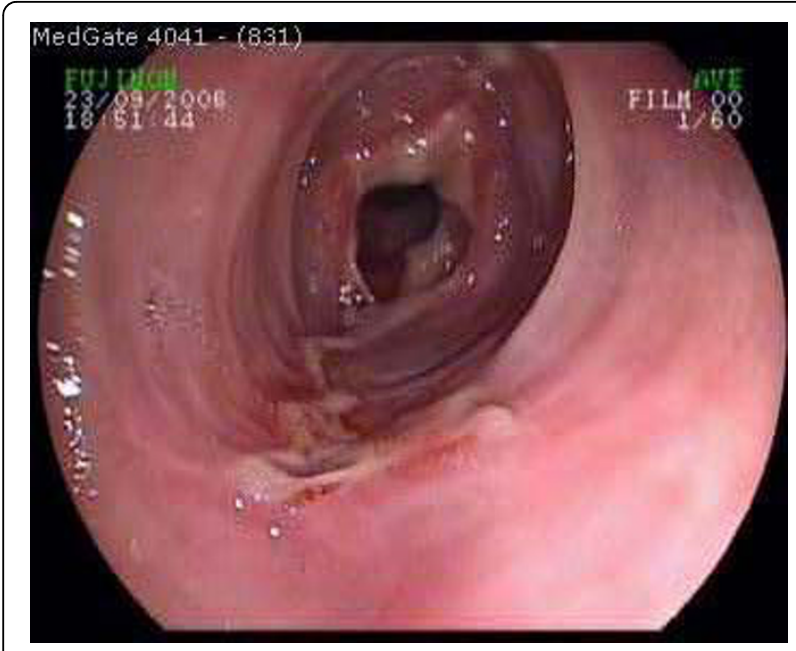

Figure $1 \mathrm{~A}$ serpiginous, in part circumferential mid-esophageal ulcer extending to the distal portion in the presence of normal squamo-columnar junction.

\section{Discussion}

Approximately 100 types of drugs have been incriminated in the etiology of around 1,000 cases of druginduced esophageal injury (DIEI). The precise mechanism is not well explained. Multiple factors, including the increasing age, decreased esophageal peristalsis and external compression are predisposing to DIEI [3]. But it is noteworthy that among the reported cases of druginduced injury, the proportion of the patients having a motility disorder such as achalasia and scleroderma or an anatomical narrowing such as tumor or stricture is low [3]. Furthermore, drugs that have a large size and sticky surface are retained longer in the esophagus [4-6]. In addition to these a clinical and experimental study has shown that doxycycline capsules remain three times longer in the esophagus than doxycycline tablets [7].

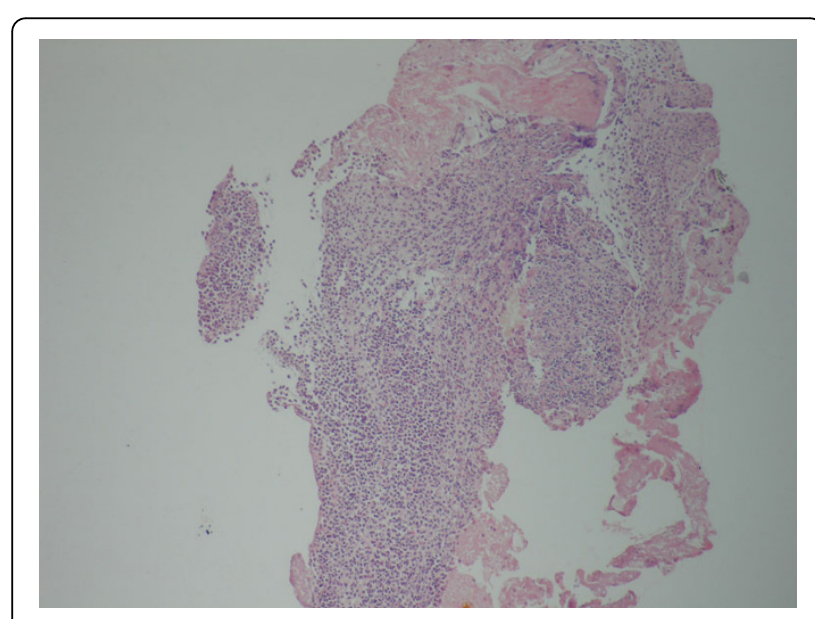

Figure 2 Dense inflammatory infiltrate around the ulcer base (HEx40).
Esophageal damage mostly occurs at the level of physiological narrowings (aortic arch level or above the lower esophageal sphincter) where the drugs tend to stick [4]. For this reason it seems to be of utmost importance to take high risk drugs with sufficient amount of water.

The most common endoscopic finding is ulcers in varying size, and depth. In very rare cases a stricture formation requireing consequent mechanical dilation may be observed [3]. Esophageal perforation and hemorrhage are rare as well but are life-threatening complications that require immediate specific and aggressive treatment.

The main step of treatment should be the withdrawal of the offending drug. The value of antacids, anti-secretory drug and proton pump inhibitors remain questionable in patients without gastroesophageal reflux [5,7]. Apart from sucralfate, no data from the literature have suggested the benefit of acid suppression [4]. Severe odynophagia rarely requires parenteral hydration or, if prolonged, total parenteral nutrition. Fortunately, in the majority of patients, DIEI symptoms resolve within one week [8].

In conclusion, after an thorough literature search in Pubmed using the keywords AZM and esophagitis, to our knowledge this is the first such a case of AZM -induced esophageal ulceration. We think that a little time taken by the physician to warn the patients for taking every oral drug with sufficient amount of water might prevent this kind of complications.

\section{Consent}

Written informed consent was obtained from the patient for publication of this case report and accompanying images. A copy of the written consent is available for review by the Editor-in-Chief of this journal.

\section{Abbreviations \\ AZM: azithromycin; DIEl: drug-induced esophageal injury}

\section{Author details}

'Department of Gastroenterology, Yeditepe University Medical Faculty, Devlet Yolu Cad 102-104 34752 Kozyatagi, Istanbul, Turkey. ${ }^{2}$ Department of Internal Medicine, Yeditepe University Medical Faculty, Devlet Yolu Cad 10210434752 Kozyatagi, Istanbul, Turkey. ${ }^{3}$ Department of Pathology, Yeditepe University Medical Faculty, Devlet Yolu Cad 102-104 34752 Kozyatagi, Istanbul, Turkey.

\section{Authors' contributions}

UA performed the upper endoscopy and endoscopic biopsies. YE, FFY, and IVS were major contributors in writing the manuscript. IDE performed the histological examination. CP performed the second look endoscopy.

All authors have read and approved the final manuscript.

\section{Competing interests}

The authors declare that they have no competing interests. 


\section{References}

1. Bott S: Medication-induced esophageal injury: survey of the literature. Am J Gastroenterol 1987, 82:758-763.

2. Kadayifci A, Gulsen MT, Koruk M, Savas MC: Doxycycline-induced pill esophagitis. Dis Esophagus 2004, 17:168-171.

3. Baehr PH, McDonald GB: Esophageal disorders caused by infection, systemic illness, medications, radiation, and trauma. Gastrointestinal and Liver Disease Philadelphia: WB SaundersIFeldman M, Scharschmidt BF, Sleisenger MH , 6 1998, 519-539.

4. Kikendall JW: Pill esophagitis. J Clin Gastroenterol 1999, 28:298-305.

5. Boyce HW: Drug-induced esophageal damage: diseases of medical progress. Gastrointest Endoscopy 1998, 47:547-550.

6. Hey H, Jorgensen F, Sorensen K, Hasselbach H, Wamberg T: Esophageal transit of six commonly used tablets and capsules. BMJ 1982, 285:1717-1719.

7. Carlborg B, Densert O, Lindqvist C: Tetracycline-induced esophageal ulcers. A clinical and experimental study. Laryngoscope 1983, 93:184-187.

8. Al-Mofarreh MA, Al Mofleh IA: Esophageal ulceration complicating doxycycline therapy. World J Gastroenterol 2003, 9:609-611.

doi:10.1186/1757-1626-3-48

Cite this article as: Akyuz et al: Severe odynophagia in a patient developing after azithromycin intake: a case report. Cases Journal 2010 3:48.

\section{Submit your next manuscript to BioMed Central} and take full advantage of:

- Convenient online submission

- Thorough peer review

- No space constraints or color figure charges

- Immediate publication on acceptance

- Inclusion in PubMed, CAS, Scopus and Google Scholar

- Research which is freely available for redistribution

Submit your manuscript at www.biomedcentral.com/submit
Ciomed Central 